\title{
Geographical variations in the benefit of applying a prioritization system for cataract surgery in different regions of Spain Rubén Román ${ }^{1}$, Mercè Comass ${ }^{1}$, Javier Mar², Enrique Bernal ${ }^{3}$, Alberto Jiménez-Puente ${ }^{4}$, Santiago Gutiérrez-Moreno ${ }^{5}$, Xavier Castells* ${ }^{*}$ and the IRYSS Network Modelling Group
}

Address: ${ }^{2}$ Evaluation and Clinical Epidemiology Department, Institut Municipal d'Assistència Sanitària (IMAS), Passeig Marítim, 25-29, 08003, Barcelona, Spain, ${ }^{2}$ Health Management Department, Hospital Alto Deba (Osakidetza), Avenida Navarra 16, 20500, Mondragón, Spain, ${ }^{3}$ Health Services Research Department, Instituto Aragonés de Ciencias de la Salud, Gómez Laguna 25, 50009, Zaragoza, Spain, ${ }^{4}$ Evaluation Department, Hospital Costa del Sol, Ctra. Nacional 340 Km 187, 29600, Marbella, Spain and ${ }^{5}$ Evaluation and Planification Department, Canarian Health Department, Pérez de Rozas 5, 38004 Santa Cruz de Tenerife, Canary Islands, Spain

Email: Rubén Román - rroman@imas.imim.es; Mercè Comas - mcomas@imas.imim.es; Javier Mar - javier.marmedina@osakidetza.net; Enrique Bernal - ebernal.iacs@aragob.es; Alberto Jiménez-Puente - ajpuente@hcs.es; Santiago Gutiérrez-Moreno - sangumo@hotmail.com; Xavier Castells* - xcastells@imas.imim.es; the IRYSS Network Modelling Group - rroman@imas.imim.es

* Corresponding author

Published: 4 February 2008

BMC Health Services Research 2008, 8:32 doi:10.1 186/1472-6963-8-32
Received: 15 May 2007

Accepted: 4 February 2008

This article is available from: http://www.biomedcentral.com/l472-6963/8/32

(C) 2008 Román et al; licensee BioMed Central Ltd.

This is an Open Access article distributed under the terms of the Creative Commons Attribution License (http://creativecommons.org/licenses/by/2.0), which permits unrestricted use, distribution, and reproduction in any medium, provided the original work is properly cited.

\begin{abstract}
Background: In Spain, there are substantial variations in the utilization of health resources among regions. Because the need for surgery differs in patients with appropriate surgical indication, introducing a prioritization system might be beneficial. Our objective was to assess geographical variations in the impact of applying a prioritization system in patients on the waiting list for cataract surgery in different regions of Spain by using a discrete-event simulation model.

Methods: A discrete-event simulation model to evaluate demand and waiting time for cataract surgery was constructed. The model was reproduced and validated in five regions of Spain and was fed administrative data (population census, surgery rates, waiting list information) and data from research studies (incidence of cataract). The benefit of introducing a prioritization system was contrasted with the usual first-in, first-out (FIFO) discipline. The prioritization system included clinical, functional and social criteria. Priority scores ranged between 0 and 100, with greater values indicating higher priority. The measure of results was the waiting time weighted by the priority score of each patient who had passed through the waiting list. Benefit was calculated as the difference in time weighted by priority score between operating according to waiting time or to priority.
\end{abstract}

Results: The mean waiting time for patients undergoing surgery according to the FIFO discipline varied from 1.97 months $(95 \% \mathrm{Cl} \mathrm{I.85;} 2.09)$ in the Basque Country to 10.02 months $(95 \% \mathrm{Cl} 9.91$; 10.12$)$ in the Canary Islands. When the prioritization system was applied, the mean waiting time was reduced to a minimum of 0.73 months weighted by priority score $(95 \% \mathrm{Cl} 0.68 ; 0.78)$ in the Basque Country and a maximum of 5.63 months $(95 \% \mathrm{Cl} 5.57 ; 5.69)$ in the Canary Islands. The waiting time weighted by priority score saved by the prioritization system varied from 1.12 months (95\% Cl I.07; I.16) in Andalusia to 2.73 months $(95 \% \mathrm{Cl} 2.67 ; 2.80)$ in Aragon.

Conclusion: The prioritization system reduced the impact of the variations found among the regions studied, thus improving equity. Prioritization allocates the available resources within each region more efficiently and reduces the waiting time of patients with greater need. Prioritization was more beneficial than allocating surgery by waiting time alone. 


\section{Background}

In the last few decades, cataract surgery rates have markedly increased in Western countries. This increase has been due to progressive population aging, improved surgical procedures and broadening of the indication criteria for cataract surgery produced by these improvements [14]. Broadening the indication criteria entails that patients with different disability levels can benefit from surgery, modifying the profile of people with unmet needs.

In Spain, the National Health System is decentralized in 17 regions. Each regional health system plans and manages their resources. Important variations in the utilization of health resources have been observed, especially in the elective surgery rate[5]. Studies evaluating the impact of different health policies on the management of need and demand, as well as resource utilization are useful in decision-making[6].

Recently, several health systems have considered the need to prioritize patients on waiting lists, which would entail modification of the current first-in, first-out (FIFO) principle through other models based on need [7-11]. Broadening the indication criteria for cataract surgery entails that the need for surgery differs in patients with appropriate surgical indication. Prioritization of patients by an explicit criterion other than the current FIFO principle would not only avoid unnecessary suffering but it is also expected to reduce the differences between the public demand and the health system utilization in terms of an improved efficiency. In Spain, a recent project has developed prioritization criteria for cataract surgery[12,13]. The objective was to create a prioritization system to ensure shorter waiting times for those patients with greater need, thus increasing the system's efficiency. The resulting prioritization system was obtained using the conjoint analysis technique, and includes clinical (visual impairment and recovery probability), functional (difficulty in doing activities of daily living and ability to work) and social (have someone to look after the patient and be a caregiver) criteria. The most weighted criterion was visual impairment, followed by limitation in doing activities of daily living. Possible priority scores range between 0 and 100, higher scores representing greater need. Thus, in this system, need and priority are equivalent. A pilot study to assess the introduction of the prioritization system in clinical practice was carried out in Catalonia[14] and, Andalusia and Aragon[15].

The effect of introducing a prioritization system would differ in each region because health systems vary widely in terms of clinical practice and utilization rates. Studying these variations is of special interest within the Spanish health system, which provides universal coverage, given that each region manages its own resources.
Simulation techniques can be used to evaluate the impact of introducing a prioritization system in different health management scenarios. Discrete-event simulation (or queuing theory) is an appropriate tool for analyzing waiting lists [16-19], because waiting lists reflect a situation of scarcity and competition for resources, and entries to and exits from the waiting list follow a stochastic law. We defined several hypotheses about what we expected from the simulation model: 1) the prioritization system redistributes the overall waiting time across patients differently than the FIFO system by beneficiating those patients with greater need; 2) differences among regions in the benefit of applying the prioritization system will be due to differences in: surgery Rate, waiting list size and priority score distribution; 3 ) the model accurately reflects the real system. Several previous experiences have taken advantage of simulation to assess prioritization of demand [17-20] and needs assessment in health services[21,22]. Our objective was to assess geographical variations in the impact of applying a prioritization system in patients on the waiting list for cataract surgery in different regions of Spain, through a discrete-event simulation model.

\section{Methods}

\section{Discrete-event simulation model}

A conceptual model to represent the natural process of cataract, from incidence to surgery (Figure 1) was discussed and agreed on by a multidisciplinary expert panel composed of ophthalmologists, epidemiologists, health economists and statisticians. The model referred to individuals from the general population, aged 50 years or older, at risk of need for cataract surgery, and focused on the Spanish health system. The conceptual model was developed by taking into account demand, as well as the particular characteristics, in each of the regions studied: Aragon, Andalusia, Basque Country, the Canary Islands and Catalonia, which represent $45.7 \%$ of the Spanish population.

The indication criterion for cataract surgery was defined as any lens opacity causing a visual acuity of 0.5 or less, on a scale from 0 to 1 , lower values indicating worse visual acuity[23]. Surgery for this indication was always considered to be appropriate. Need for cataract surgery was defined as meeting the indication criteria for surgery. Incidence was defined as the occurrence of need for surgery.

Need for cataract surgery (Figure 1) was separated into "Non-Expressed Need" and "Waiting List". The state of "Non-Expressed Need" represented the population that, although meeting the indication criteria for surgery, was not included on a waiting list of the Spanish health system. Expressing need was considered equivalent to the following process: requesting surgery and being indicated by a specialist and included on a waiting list of the health sys- 


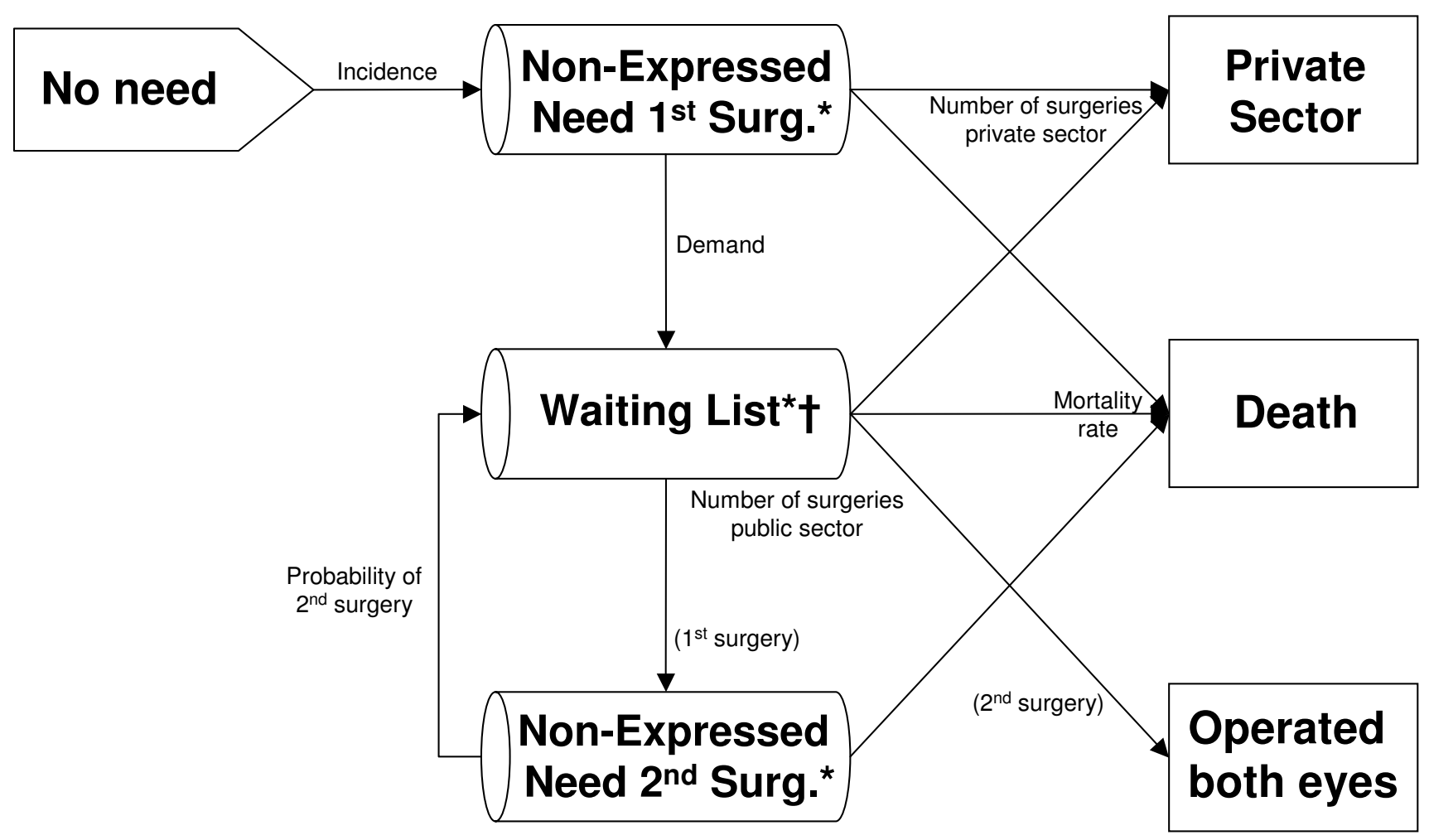

\section{Figure I}

Conceptual model. *: Prevalence of need is divided among these 3 states. $\dagger$ : Cases in the waiting list have the priority score as an additional attribute.

tem. A distinction was made between first- and secondeye surgery in the "Non-Expressed Need" state (Figure 1), given that senile cataracts are mainly bilateral and interventions are performed in one eye at a time. This distinction was not made in the waiting list, given that the waiting list does not distinguish between patients waiting for first- and those waiting for second-eye surgery. The activity carried out in the private sector was taken into account, given that its activity is high.

\section{Parameter estimation}

The information needed to estimate the model's parameters was compiled for each region studied. Different information sources were used (Table 1), including administrative and research databases. When data from the study's setting were unavailable, data from similar settings was used. The Hospital Discharge Minimum Data Set (HDMDS) of at least three consecutive years was obtained for each of the five regions. This database records all the operations performed in the public sector and allows bilateral operations to be identified. The cataract surgery rates performed in the public sector and the probability of second-eye surgery were obtained from the HDMDS.
Because we used a continuous-time model, the parameters of transitions between states were estimated as distributions of time to an event. Moreover, the possible changes in parameters throughout the 5-year time horizon were taken into account, such as the increase in the number of operations, the probability of second eye surgery[24] or the monthly number of entries to the waiting list (table 1). Since primary data on the prevalence of cataracts in Spain is lacking, a systematic review of prevalence studies of cataracts was carried out[25]. Based on this review the database of the North London Eye Study was used, a population-based study on the prevalence of eye diseases in North London[26]. Prevalence was calculated by age and sex, and its estimates were projected onto the population of each of the five regions studied. In the absence of incidence data, prevalence was used to estimate incidence[27]. The number of inhabitants in each region, as well as the number of deaths by age and sex, in 2001 was obtained from the Spanish National Statistics Institute.

The number of monthly entries to the waiting list in 2003 and the number of patients waiting were obtained from the waiting lists register of each region's health system. 
Table I: Simulation model parameters, source of information and distribution function.

\begin{tabular}{|c|c|c|}
\hline Parameter & Source & Distribution \\
\hline \multicolumn{3}{|l|}{ Related to initial state } \\
\hline Non Expressed Need Ist Surgery Backlog & North London Eye Study & Fixed value \\
\hline Non Expressed Need 2nd Surgery Backlog & North London Eye Study & Fixed value \\
\hline Waiting List Backlog & Waiting list register & Fixed value \\
\hline Proportion of patients waiting for $2^{\text {nd }}$ eye surgery & Pilot Study (Empirical) & Fixed value \\
\hline \multicolumn{3}{|l|}{ Static parameters } \\
\hline Incident cases per month & North London Eye Study & Poisson* \\
\hline Number of operations in the private sector per month & Hospital Discharge Minimum Data Set & Poisson* \\
\hline $\begin{array}{l}\text { Proportion of cases of the waiting list who switch to the private } \\
\text { sector }\end{array}$ & Pilot Study (Empirical) & Bernoulli \\
\hline Top limit for waiting list contents (self-regulation) & Opportunistic & Fixed value \\
\hline Increase in priority score & Pilot Study (Empirical) & Fixed value \\
\hline Time between revisions of priority score & Pilot Study (Empirical) & Fixed value \\
\hline Mortality & Spanish Mortality Register & Empirical lifetime density function \\
\hline \multicolumn{3}{|l|}{ Dynamic parameters } \\
\hline Number of surgeries per month & Hospital Discharge Minimum Data Set & Poisson* \\
\hline Probability of second eye surgery & Hospital Discharge Minimum Data Set & Bernoulli \\
\hline Number of bilateral cases entering the waiting list per month & Waiting list register & Poisson* \\
\hline
\end{tabular}

*Poisson distributions were generated as time between arrivals of the events through an Exponential distribution

The pilot study to assess the introduction of the prioritization system in clinical practice with data from Catalonia[14], Andalusia and Aragon[15] was used to calculate the distributions of priority score at entry to the waiting list, as well as the proportions of patients with bilateral cataract or aphakia (those who had already undergone surgery in one eye). Different empirical distributions were used for bilateral and aphakic patients because statistically different scores were found for first- and second-eye surgery. In the absence of priority data for the Canary Islands and the Basque Country, in these two regions we used a pooled priority distribution of the three regions for which priority data was available. As the prioritization system included clinical and functional criteria that may worsen over time, an increase in priority score with time was evaluated and introduced. Table 1 summarizes the parameters introduced in the model and their sources of information and distribution functions.

Geographical variation was measured through rates (number of occurrences per 100,000 inhabitants), high/ low ratio for rates, and coefficient of variation, defined as the ratio of the standard deviation relative to the mean.

\section{Simulation}

The conceptual model (Figure 1) was implemented as a discrete-event simulation model in the SIMUL8 v.10 package (SIMUL8 Corporation) [28] and was run with the corresponding data from each region. The time units were months and the simulation horizon was 60 months (5 years). Each patient was assigned a set of attributes, including age, sex, priority for first- and second-eye sur- gery (when applicable), "type" of patient (bilateral or aphakic) and lifetime. The priority scores were generated when a patient entered the waiting list and took into account whether the patient had bilateral cataracts or aphakia.

As the impact of the time waited depends on the level of need, the measure of results used as the main outcome was waiting time weighted by priority score, which can be interpreted as the time that a patient waits, due to the waiting list, weighted by his/her need for surgery. This measure allowed waiting times to be compared by taking into account how these times were assigned according to each patient's priority level. Thus, the difference between two simulations could be interpreted as the time, weighted by need, saved or lost with the prioritization system versus the FIFO discipline. The waiting time weighted by priority score included all patients who entered the waiting list: those undergoing surgery, those who were still waiting at the end of the simulation period, those who switched to the private sector, and those who died while on the waiting list. Trials were performed including 20 independent replications, each beginning with the same initial conditions. This sample size was calculated to obtain sufficient precision for comparison between waiting list disciplines[16]. The analyses were based not only on the waiting time weighted by priority score, but also on the raw waiting time of patients. Different thresholds of priority score according to eventual fixed guarantee times were calculated. These thresholds indicated the minimum priority score needed to be operated under a given guarantee time 
Table 2: Descriptive information on senile cataracts in the autonomous regions studied.

\begin{tabular}{|c|c|c|c|c|c|}
\hline & \multicolumn{5}{|c|}{ Regions } \\
\hline & Andalusia & Aragon & Basque Country & Canary Islands & Catalonia \\
\hline Population & $7,357,558$ & $1,204,215$ & $2,082,587$ & $1,694,477$ & $6,343,110$ \\
\hline Population Over 50 years & $2,142,202$ & 457,631 & 744,419 & 449,819 & $2,164,467$ \\
\hline \% Population Over 50 years & $29 \%$ & $38 \%$ & $36 \%$ & $27 \%$ & $34 \%$ \\
\hline \multicolumn{6}{|l|}{ Prevalence } \\
\hline$\%$ Prevalence in people over 50 years & $22.4 \%$ & $25.8 \%$ & $22.8 \%$ & $20.4 \%$ & $23.5 \%$ \\
\hline \multicolumn{6}{|l|}{ Surgery rate * } \\
\hline Yearly rate & 405 & 529 & 607 & 440 & 685 \\
\hline Surgery rate in people over 50 years & I,39| & $\mathrm{I}, 392$ & $\mathrm{I}, 724$ & 1,650 & 2,156 \\
\hline Waiting List & 9,205 & 2,826 & 2,313 & 5,771 & 19,586 \\
\hline$\%$ of prevalent population & $1.9 \%$ & $2.4 \%$ & $1.4 \%$ & $6.3 \%$ & $3.8 \%$ \\
\hline Waiting List entry rate (2003) * & 612 & 755 & 656 & 602 & 733 \\
\hline \multicolumn{6}{|c|}{ Mean priority (at entry to the waiting list) } \\
\hline First surgery (SD) & $47.1(19.9)$ & $28.3(22.4)$ & $39.3(22.7) \dagger$ & $39.3(22.7) \dagger$ & $36.5(22.8)$ \\
\hline Second surgery (SD) & $36.8(22.3)$ & $13.7(\mid 1.7)$ & $28.8(22.6)^{\dagger}$ & $28.8(22.6)^{\dagger}$ & $26.1(22.2)$ \\
\hline
\end{tabular}

$* \mathrm{~N}^{\circ}$ of ocurrences/ $/ 00,000$ inhabitants

$\dagger$ A pooled Distribution was used in the absence of empirical data

SD: Standard Deviation.

\section{Results}

The expert panel evaluated the model's results and considered them to be valid and credible. Different patterns of aging were found among regions: Aragon, Catalonia and the Basque Country showed the greatest ageing, with more than $34 \%$ of their populations being over 50 years of age. In Andalusia and the Canary Islands, less than 30\% of the population was over 50 years old. The estimated percentage of the population with need for cataract surgery was between one-fifth and one-fourth of the population over 50 years of age in all the regions studied (Table 2).

A coefficient of variation (COV) of 0.24 was found in surgery rates among the regions studied. In particular, the surgery rates found in Catalonia were greater than those in the Canary Islands and Andalusia (high/low ratio 1.76 and 1.69 respectively). The rates of entries to the waiting list were more homogeneous among regions than the surgery rates (COV: 0.1). The percentage of the prevalent population included on a waiting list was less than $6.5 \%$ in all regions. This percentage varied among the regions studied (COV: 0.62), Table 2. The results of the pilot study $[14,15]$ showed significant differences in the mean priority score at entry to the waiting list among the three regions for which data were available (data not shown). Priority scores showed a dispersion that covered the entire range of possible values. The 25th and 75th percentiles of the assigned priority scores were 34 and 62 points respectively for first-eye surgery and 20 and 53 points for second-eye surgery in Andalusia, 7 and 46 for first-eye surgery and 6 and 21 for second-eye surgery in Aragon, and 20 and 52 for first-eye surgery and 6 and 41 for second-eye in Catalonia.

Simulation of the current waiting list scenario (FIFO) showed that the raw mean waiting time of patients who underwent surgery in the public sector varied from 1.97 months $(95 \%$ CI $1.85 ; 2.09)$ in the Basque Country to 10.02 months $(95 \%$ CI 9.91; 10.12) in the Canary Islands, Table 3. When the prioritization system was applied, the mean waiting time was reduced to 0.73 months weighted by priority score $(95 \%$ CI $0.68 ; 0.78)$ in the Basque Country (lowest value) and 5.63 months (95\% CI 5.57; 5.69) in the Canary Islands (highest value), Table 3. However, patients still waiting at the end of the simulation period had longer waiting times with the prioritization system than with the FIFO discipline. Differences of 11.3 raw months $(95 \%$ CI $9.4 ; 13.3)$ in Andalusia, 4.7 months (95\% CI 4.3; 5.1) in Aragon, 5.8 months (95\% CI 5.3; 6.4) in the Basque Country, 12.4 months (95\% CI 11.0; 13.7) in the Canary Islands and 6.9 months (95\% CI 6.2; 7.6) in Catalonia were found. Patients who died while on the waiting list also had longer mean waiting times with the prioritization system than with the FIFO discipline, with waiting times increased by 8.3 months (95\% CI 7.3; $9.4)$ in Andalusia, 4.4 months $(95 \%$ CI $3.9 ; 4.8)$ in Aragon, 5.3 months $(95 \%$ CI $4.7 ; 5.9)$ in the Basque Country, 8.8 months $(95 \%$ CI $8.0 ; 9.6)$ in the Canary Islands and 5.8 months $(95 \%$ CI 5.2; 6.5) in Catalonia.

The overall mean waiting time weighted by priority score, that is, considering each patient who entered the waiting list (operated patients, patients still waiting at the end of the simulation period, patients who switched to the pri- 
Table 3: Raw waiting times (FIFO) and times weighted by priority score (FIFO, prioritization system)

\begin{tabular}{|c|c|c|c|c|c|c|c|c|}
\hline & \multirow{2}{*}{\multicolumn{2}{|c|}{ Raw waiting times (FIFO) }} & \multicolumn{6}{|c|}{ Waiting times weighted by priority score } \\
\hline & & & \multicolumn{2}{|c|}{ FIFO System } & \multicolumn{2}{|c|}{ Prioritization system } & \multicolumn{2}{|c|}{ Benefit of the priorization system } \\
\hline & Mean & SD & Mean & SD & Mean & SD & Mean & SD \\
\hline Andalusia & 2.91 & {$[0.09]$} & 2.81 & {$[0.09]$} & 1.69 & {$[0.11]$} & 1.12 & {$[0.08]$} \\
\hline Aragon & 5.19 & {$[0.21]$} & 4.89 & {$[0.18]$} & 2.16 & {$[0.12]$} & 2.73 & {$[0.12]$} \\
\hline Basque Country & 1.97 & {$[0.27]$} & 1.93 & {$[0.26]$} & 0.73 & {$[0.11]$} & 1.20 & {$[0.16]$} \\
\hline Canary Islands & 10.02 & {$[0.24]$} & 7.23 & {$[0.21]$} & 5.63 & {$[0.13]$} & 1.60 & {$[0.16]$} \\
\hline Catalonia & 4.48 & {$[0.57]$} & 4.26 & {$[0.52]$} & 1.99 & {$[0.36]$} & 2.27 & {$[0.20]$} \\
\hline
\end{tabular}

FIFO: First-in, first-out. SD: Standard Deviation.

vate sector and patients who died while on the waiting list), was reduced in all the regions when the prioritization system was applied. The waiting time weighted by priority score saved by the prioritization system was 1.12 months $(95 \%$ CI $1.07 ; 1.16)$ in Andalusia, 2.73 months (95\% CI 2.67; 2.80) in Aragon, 1.20 months (95\% CI $1.11 ; 1.28)$ in the Basque Country, 1.60 months $(95 \% \mathrm{CI}$
$1.51 ; 1.69)$ in the Canary Islands and 2.27 months $(95 \%$ CI $2.17 ; 2.38$ ) in Catalonia, Table 3.

Figure 2 shows the relationship between the priority score and the waiting time under the prioritization system, i.e., the minimum priority score required for a patient to undergo surgery under an eventual guarantee time, fixed at 3, 6, 12, 18 and 24 months. In patients with a priority

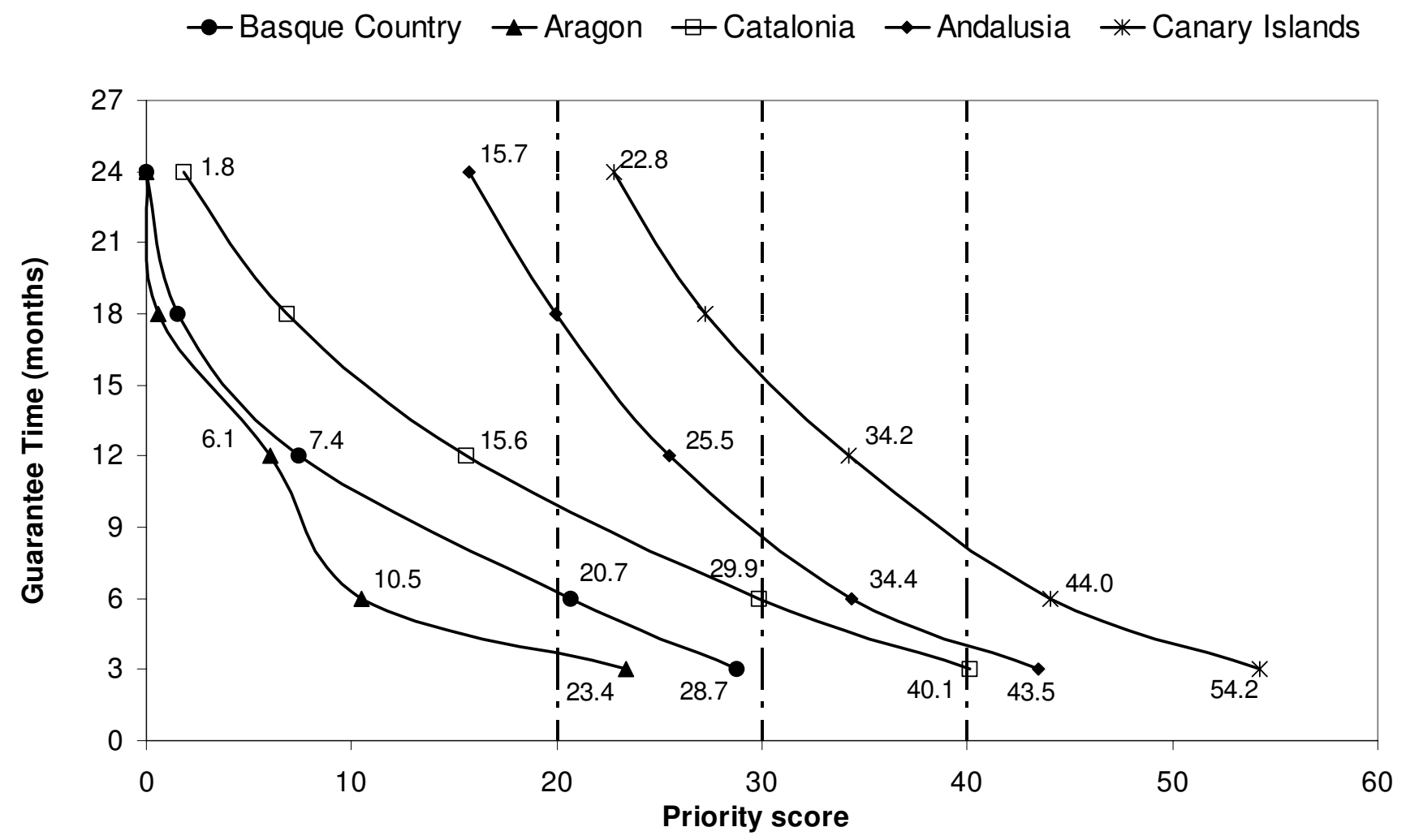

Figure 2

Minimum priority scores for guarantee times. 
score at entry to the waiting list of 40 or more points, the maximum guarantee time was 4 months in Andalusia, 1 month in Aragon, 1 month in the Basque Country, 8.5 months in the Canary Islands and 3 months in Catalonia. In addition, as the priority score at entry in the waiting list diminished, the maximum guarantee time increased. Patients with less than 20 points waited 18 months or more in Andalusia, more than 4 months in Aragon, more than 6 months in the Basque Country, more than 24 months in the Canary Islands, and more than 10 months in Catalonia. A decreasing trend was observed in differences in waiting time among regions as priority scores increased.

When the prioritization system was applied the waiting time range among regions was reduced in 10.64 months for patients within the 20-29 priority score interval with respect to patients in the 60-69 priority score interval, Table 4. Under the current waiting list scenario (FIFO) there was no reduction in the waiting time range among regions. This range held constant around 8 months among all the priority score groups, Table 4 .

\section{Discussion}

The model described allows several factors commonly used separately by decision-makers to be integrated into a complex but understandable system. Our findings show firstly that introducing a prioritization system improved the impact of cataract procedures by minimizing waiting time in patients according to their level of need and secondly that the benefit of applying the prioritization system varied substantially, depending on the specific characteristics of each region's local health system.

To measure the impact of waiting in accordance with patient's need, the waiting time weighted by priority score was used. Although this measure was based on individual data, it can be interpreted as a global measure of benefit since it took into account the priority scores of all patients who had been assigned a priority score. This measure is based on patients' need and not on health benefit. Unpublished analyses on the prioritization system showed that correlation between the priority score and the utility questionnaires EQ-5D and HUI-3 is low (0.1 and 0.15 , respectively). As there is no evidence of relationship between need (priority) and benefit (utility), results were based on need only. The prioritization system reduced the waiting time up to half the time under the actual FIFO discipline (table 3). The waiting time was not measured at a fixed time point; instead it was measured as the average waiting time throughout the time horizon for all patients. Application of the priority system redistributed the total time waited across patients. The model shows how patients with greater need waited less than those with low levels of need. Previous experiences have concluded that assigning surgery according to priority criteria is more beneficial than assignation by waiting time [17-19]. Although the prioritization system was beneficial as a whole, patients with low priority scores had very long waiting times. However, application of the prioritization system should guarantee a maximum waiting time to these patients. Dunn et al.[29] showed that $80 \%$ of patients rated waits of 3 months or less as acceptable, while $25 \%$ regarded waits of 6 months or longer as too long. Moreover, patients with greater disability were those less tolerant with waiting times.

Several studies have observed geographical variations in clinical practice worldwide[30]. Most of the results found in other countries can be extrapolated to Spain, which offers universal coverage. In agreement with previous studies[31,32], the variation in clinical practice found among regions is notable. Nevertheless, the reasons for this variation are difficult to identify. A small percentage could be explained by demographic and morbidity characteristics of the populations but the main reasons are management features and the availability of resources. The results obtained suggest that prioritization systems reduce geographical variations in waiting time in patients with higher levels of need, that is, in those with high pri-

Table 4: Maximum and minimum waiting time weighted by priority score for given priority scores (FIFO and prioritization system)

Waiting times weighted by priority score

\begin{tabular}{|c|c|c|c|c|c|c|}
\hline \multirow[t]{2}{*}{ Priority Scores } & \multicolumn{3}{|c|}{ FIFO System } & \multicolumn{3}{|c|}{ Prioritization System } \\
\hline & Maximum* & Minimum ${ }^{\dagger}$ & Difference & Maximum* & Minimum $^{\dagger}$ & Difference \\
\hline $20-29$ & 10.01 & 1.96 & 8.05 & 11.32 & 0.54 & 10.78 \\
\hline $30-39$ & 10.01 & 1.97 & 8.04 & 2.75 & 0.17 & 2.58 \\
\hline $40-49$ & 10.01 & 1.97 & 8.04 & 1.01 & 0.08 & 0.93 \\
\hline $50-59$ & 10.02 & 1.97 & 8.05 & 0.34 & 0.04 & 0.3 \\
\hline $60-69$ & 10.02 & 1.97 & 8.05 & 0.17 & 0.03 & 0.14 \\
\hline
\end{tabular}

* Maximum waiting times belong to the Canary Islands (see table 3)

† Minimum waiting times belong to the Basque Country (see table 3) 
ority scores. Differences among regions in the overall waiting times were reduced when applying the prioritization system. The overall rank between the regions with the maximum and the minimum mean waiting time is reduced from 8.1 months under the FIFO discipline to 4.9 with the prioritization system. Table 4 shows how under the prioritization system the waiting time range among the regions was reduced as the priority score increased. Differences among patients with high priority scores were reduced substantially, while the results were uncertain in patients with medium or low priority scores.

The impact of introducing the prioritization system varied substantially among the regions studied, but reduced inequities among regions in patients with greater need. Figure 2 shows that the curves for Andalusia and Catalonia became closer as the priority score increases. Patients with a priority score of 40 had similar waiting times in both regions ( 4 months in Andalusia and 3 months in Catalonia), while differences in waiting time increased substantially in patients with priority scores of 20 (18 months in Andalusia and around 11 months in Catalonia). This pattern, however, was not observed when comparing the curves among Catalonia and Aragon, which maintained the differences among curves independently of priority score. To sum up, the prioritization system improves equity in patients with greater need, but not necessarily in all other patients.

In the present study, the variability found in surgery rates was not related to population characteristics or to the needs of the population on the waiting list. This lack of association indicates the need to improve the effectiveness of some management policies. Less than $6.5 \%$ of the population with need for surgery is included on a waiting list and there is wide variability in the priority scores assigned. Waiting lists do not represent unmet needs, but rather an auto-regulation mechanism of the health system. If the surgery supply is insufficient to cover unmet needs, it seems reasonable to introduce prioritization systems, which involve modifying the indication thresholds in accordance with the resources available in the system. The effectiveness of prioritization systems would increase substantially if prioritization was applied at surgery indication instead of assigning priorities only to patients entering the waiting list. If there is a substantial unmet need, clinicians could decide not to refer patients with low priorities for surgery, as they would have excessive waiting times. This fact would have an impact on the indication criterion. Giving a guarantee time to each patient related to his/her level of need would further increase equity, since levels of need in patients on the waiting list differ widely. Thus, the introduction of a prioritization system should entail an analysis of the unmet needs in each region, or at least involve a reduction in the variations in the surgery rates among regions.

The variables that appeared to have the greatest influence on the benefit obtained from the prioritization system and its impact in the waiting time were the variability in the priority scores at entry to the waiting list, the surgery rate and the waiting list volume. It is expected that the greater the waiting list and the lower the surgery rate within each region, the greater the benefit of introducing the prioritization system, as this would increase the waiting of patients and thus the benefit from introducing the prioritization system. Moreover, the higher the variability within each region in the priority scores assigned to patients, the higher the impact that can be expected from the prioritization system. If all patients had the same priority score, prioritization would have no impact.

Using data from the North London Eye Study might introduce some bias to the prevalence estimation. However a systematic review of cataract prevalence studies carried out by this research team[25] showed little differences in the prevalence by age among studies performed in several countries with populations similar to the Spanish population. This result minimizes the possible bias caused by assuming that the same cataract prevalence applies to North London and Spain. We assume that little differences in cataract prevalence would be found among Spanish regions because differences were small among international studies. The effect of the prioritization system might be overestimated because pure FIFO systems are rare and clinicians might use some implicit prioritization. However, a pilot study carried out by Espallargues et al.[14] found a slight prioritization in the Spanish cataract surgery waiting list. We defined several mathematical functions to approximate the relationships among certain parameters within the system. Thus, the quality of the information introduced in the model strongly depended on the quality of the information obtained from the different regions[16]. However, all the estimations made were validated by a panel of experts and consensus was reached by all regions' representatives. Some characteristics were estimated through data from other regions when access to the source of information was limited or information was unavailable.

\section{Conclusion}

Discrete-event simulation is an appropriate and robust tool to study the impact and benefits of different health policy interventions in a context in which resources are scarce and there is wide variability in their management[16]. Introducing the prioritization system allows the impact of variations among regions to be reduced by improving the system's equity and effectiveness. On the one hand, effectiveness improves because patients with 
greater need have a shorter waiting time resulting in an overall saving of waiting time weighted by need. On the other hand, equity improves because the higher the need, the greater the reduction in differences in waiting time. However, the lower the priority, the greater increase in the differences among patients. The results of this study suggest that introducing the prioritization system would allocate the available resources within each region more efficiently.

\section{Competing interests}

The author(s) declare that they have no competing interests.

\section{Authors' contributions}

All the authors have contributed to the achievement of this study. RR participated in the design of the study, the statistical analysis and drafted the manuscript. MC participated in the design of the study, the statistical analysis and helped to draft and review the manuscript. JM, EB, AJ and SG helped in the design of the study and the review of the manuscript, participated in the validation of the model and provided essential information for the development of the analysis. XC conceived the study, and participated in its design and coordination and helped to draft and review the manuscript. All authors read and approved the final manuscript.

\section{Acknowledgements}

This work was supported by grants from the Catalan Agency for Health Technology Assessment and Research, (CAHTA) (10/31/98, 089/07/2000) and the Fondo de Investigación Sanitaria (FIS) (99/0686, PI020365, G03/202, C03/09, PI052403, P1052302). The IRYSS Network (Research Network on Health Results and Health Services) Modeling Group included the following co-investigators: Lorena Hoffmeister (Hospital del Mar-IMIM); Francesc Cots (Hospital del Mar-IMIM); Mireia Espallargues (Catalan Agency for Technology Assessment and Research); Virginia Yanes (Servicio Canario de la Salud, Canary Islands). The funding bodies of the study had no role in study design, data collection, data analysis, data interpretation, writing of the report or the decision to submit the manuscript for publication.

\section{References}

I. Rutkow IM: Surgical operations in the United States. Then (1983) and now (1994). Arch Surg 1997, 132:983-990.

2. Semmens JB, Li J, Morlet N, Ng J: Trends in cataract surgery and postoperative endophthalmitis in Western Australia (19801998): the Endophthalmitis Population Study of Western Australia. Clin Experiment Ophthalmol 2003, 3 I:213-219.

3. Williams ES, Seward HC: Cataract surgery in South West Thames Region: an analysis of age-adjusted surgery rates and length of stay by district. Public Health 1993, I 07:44 I-449.

4. Lundstrom M, Stenevi U, Thorburn W: The Swedish National Cataract Register: A 9-year review. Acta Ophthalmol Scand 2002, 80:248-257.

5. Peiro S, Bernal-Delgado E: What incentives foster hospital use in the National Health Service? Gac Sanit 2006; 2006, 20 : I $10-116$.

6. Vissers JM, Van Der Bij JD, Kusters RJ: Towards decision support for waiting lists: an operations management view. Health Care Manag Sci 200I, 4: I33-|42.

7. Association BM: Waiting list prioritisation scoring systems: a discussion paper London, British Medical Association; 1999.
8. Lundstrom M, Stenevi U, Thorburn W: Assessment of waiting time and priority setting by means of a national register. Int J Technol Assess Health Care 1996, I 2: I36-I40.

9. Hadorn DC, Holmes AC: The New Zealand priority criteria project. Part I: Overview. BMJ 1997, 3 | 4: I 3 |- I 34.

10. Romanchuk KG, Sanmugasunderam S, Hadorn DC: Developing cataract surgery priority criteria: results from the Western Canada Waiting List Project. Can J Ophthalmol 2002, 37:| 45-I54.

I I. Lack A, Edwards RT, Boland A: Weights for waits: lessons from Salisbury. J Health Serv Res Policy 2000, 5:83-88.

12. Espallargues M, Sampietro L, Castells X, Pinto JL, Rodríguez E, Comas M: Elaboració d'un sistema de priorització de pacients en llista d'espera per a cirurgia de cataracta $i$ artroplàstia de maluc i genoll. Volume INO I/2003. Barcelona, Agència d'Avaluació de Tecnologia i Recerca Mèdiques. Servei Català de la Salut. Departament de Salut. Generalitat de Catalunya; 2003.

13. Sampietro-Colom L, Espallargues M, Castells X, Comas M, Pinto JL, Rodriguez E: Health Decision-Makers State their Preferences on the Priorization of Patients on Waiting List for Cataract Surgery and Total Knee/Hip Replacement. Annu Meet Int Soc Technol Assess Health Care 200 I; I 7: abstract no 2 I 42007 [http://gate way.nlm.nih.gov/MeetingAbstracts//02274546.html].

14. Espallargues M, Comas M, Sampietro-Colom L, Castells X: Prova pilot del sistema de priorització de pacients en Ilista d'espera per a cirurgia de cataracta, artroplàstia de maluc i artroplàstia de genoll (setembre 2003). Volume IN04/2004. Barcelona, Agència d'Avaluació de Tecnologia i Recerca Mèdiques. Servei Català de la Salut. Departament de Salut. Generalitat de Catalunya; 2005.

15. Allepuz A, Espallargues M, Moharra M, Bernal E, García , Martínez Medialdea S, Delgado E: Validación de un sistema de priorización de pacientes en lista de espera para cirugía de cataratas. Gac Sanit 2005, 19:8I-8I. http://external.doyma.es/pdf/I38/ I38v| 9nSupl. Ia I 3080377pdf00 I.pdf

16. Law AM, Kelton WD: Simulation modeling and analysis 3rd edition. McGraw-Hill Companies; 2000.

17. Everett JE: A decision support simulation model for the management of an elective surgery waiting system. Health Care Manag Sci 2002, 5:89-95.

18. Tuft S, Gallivan S: Computer modelling of a cataract waiting list. $\mathrm{Br}$ J Ophthalmol 200I, 85:582-585.

19. Fantini MP, Negro A, Accorsi S, Cisbani L, Taroni F, Grilli R: Development and assessment of a priority score for cataract surgery. Can J Ophthalmol 2004, 39:48-55.

20. Ratcliffe J, Young T, Buxton M, Eldabi T, Paul R, Burroughs A, Papatheodoridis G, Rolles K: A simulation modelling approach to evaluating alternative policies for the management of the waiting list for liver transplantation. Health Care Manag Sci 200 I, 4:117-124.

21. Burkell J, Wright A, Hoffmaster B, Webb K: A decision-making aid for long-term care waiting list policies: modelling first-come, first-served vs. needs-based criteria. Healthc Manage Forum 1996, 9:35-39.

22. Davies R, Roderick P: Predicting the future demand for renal replacement therapy in England using simulation modelling. Nephrol Dial Transplant 1997, I 2:2512-2516.

23. Cataract surgery guidelines 2004 [http://www.rcophth.ac.uk]. London, The Royal College of Ophthalmologists

24. Hoffmeister L, Roman R, Comas M, Cots F, Bernal-Delgado E, Castells $X$ : Time-trend and variations in the proportion of second-eye cataract surgery. BMC Health Serv Res 2007, 7:53.

25. Acosta R, Hoffmeister L, Roman R, Comas M, Castilla M, Castells X: [Systematic review of population-based studies of the prevalence of cataracts.]. Arch Soc Esp Oftalmol 2006, 81:509-5 I6.

26. Reidy A, Minassian DC, Vafidis G, Joseph J, Farrow S, Wu J, Desai P Connolly A: Prevalence of serious eye disease and visual impairment in a north London population: population based, cross sectional study. BM] 1998, 3 I 6:1643-1646.

27. Podgor MJ, Leske MC: Estimating incidence from age-specific prevalence for irreversible diseases with differential mortality. Stat Med 1986, 5:573-578.

28. SIMUL8.com 2006 [http://www.simul8.com/]. SIMUL8 Corporation

29. Dunn E, Black C, Alonso J, Norregaard JC, Anderson GF: Patients' acceptance of waiting for cataract surgery: what makes a wait too long? Soc Sci Med 1997, 44: 1603-1610. 
30. Fisher ES, Wennberg DE, Stukel TA, Gottlieb DJ, Lucas FL, Pinder EL: The implications of regional variations in Medicare spending. Part I: the content, quality, and accessibility of care. Ann Intern Med 2003, I38:273-287.

31. Peiro S, Meneu R, Marques Espi JA, Librero J, Ordinana Calabuig R: La variabilidad en la práctica médica: relevancia, estrategias de abordaje y política sanitaria. Papeles de Economía Española 1998, Papeles de Economía Española:.

32. Bernal $E$ : Has the time arrived for the management of waiting lists? Gac Sanit 2002, 16:436-439.

\section{Pre-publication history}

The pre-publication history for this paper can be accessed here:

http://www.biomedcentral.com/1472-6963/8/32/prepub

Publish with Bio Med Central and every scientist can read your work free of charge

"BioMed Central will be the most significant development for disseminating the results of biomedical research in our lifetime. " Sir Paul Nurse, Cancer Research UK

Your research papers will be:

- available free of charge to the entire biomedical community

- peer reviewed and published immediately upon acceptance

- cited in PubMed and archived on PubMed Central

- yours - you keep the copyright

Submit your manuscript here:

http://www.biomedcentral.com/info/publishing_adv.asp 